\title{
Molecular Cloning of a cDNA Encoding an Amphid-Secreted Putative Avirulence Protein from the Root-Knot Nematode Meloidogyne incognita
}

\author{
Jean-Philippe Semblat, ${ }^{1}$ Marie-Noëlle Rosso, ${ }^{1}$ Richard S. Hussey, ${ }^{2}$ Pierre Abad, ${ }^{1}$ and Philippe \\ Castagnone-Sereno ${ }^{1}$ \\ ${ }^{1}$ INRA, Unité Santé Végétale et Environnement, BP2078, 06606 Antibes cedex, France; ${ }^{2}$ Department of \\ Plant Pathology, University of Georgia, Athens 30602-7274, U.S.A. \\ Accepted 30 September 2000.
}

\begin{abstract}
Amplified fragment length polymorphism fingerprinting of three pairs of Meloidogyne incognita near-isogenic lines (NILs) was used to identify markers differential between nematode genotypes avirulent or virulent against the tomato $M i$ resistance gene. One of these sequences, present only in the avirulent lines, was used as a probe to screen a cDNA library from second-stage juveniles (J2s) and allowed cloning of a cDNA encoding a secretory protein. The putative full-length cDNA, named map-1, encoded a 458 amino acid (aa) protein containing a predictive $\mathrm{N}$-terminal secretion signal peptide. The MAP-1 sequence did not show any significant similarity to proteins deposited in databases. The internal part of the protein, however, was characterized by highly conserved repetitive motives of 58 or 13 aa. Reverse transcription polymerase chain reaction (RT-PCR) experiments confirmed that map-1 expression was different between avirulent and virulent NILs. In PCR reactions, map-1-related sequences were amplified only in nematode populations belonging to the three species against which the $M i$ gene confers resistance: $M$. arenaria, $M$. incognita, and $M$. javanica. Polyclonal antibodies raised against a synthetic peptide deduced from the MAP-1 sequence strongly labeled $\mathbf{J} 2$ amphidial secretions in immunofluorescence microscopy assays, suggesting that MAP-1 may be involved in the early steps of recognition between (resistant) plants and (avirulent) nematodes.
\end{abstract}

Additional keywords: plant-nematode interaction, selection.

Root-knot nematodes (RKN) of the genus Meloidogyne are major threats to agricultural production worldwide, with a host range of at least 2,000 plant species. These sedentary endoparasites have evolved very complex trophic relationships with their host plants by the induction in the root tissues of specific feeding cells known as giant-cells (Williamson and Hussey 1996). Use of plant resistance is the most effective and environmentally safe method to manage RKN, especially

Corresponding author: P. Castagnone-Sereno; Fax: +33 4936789 55; E-mail: pca@antibes.inra.fr

Nucleotide sequence data is available in the EMBL database, accession number AJ278663. in solanaceous crops (Roberts 1992). In tomato, the recently cloned $M i$ resistance gene (Milligan et al. 1998) specifically controls the three major RKN species, $M$. incognita (Kofoid \& White), M. javanica (Treub), and M. arenaria (Neal). Resistance is mediated by a hypersensitive response (HR) consisting of a localized necrosis of root cells around the invading nematode (Williamson and Hussey 1996), a type of plant reaction that frequently occurs with other plant pathogens (Lamb 1994).

Even though plant resistance to pathogens is increasingly used in agriculture, damage due to RKN is still of significant economic importance. The development of virulent populations able to reproduce on resistant cultivars may contribute to this situation. Because tomato is associated with many agricultural systems worldwide, and RKN are major pests of this crop, extensive reports on the occurrence of natural biotypes virulent against the $M i$ resistance gene are available (Eddaoudi et al. 1997; Kaloshian et al. 1996; Tzortzakakis and Gowen 1996). Although $M$. incognita reproduces exclusively by mitotic parthenogenesis (Triantaphyllou 1985), the selection of lines virulent against the $M i$ gene has been achieved from avirulent nematodes under laboratory conditions, thus leading to the establishment of pairs of near-isogenic lines (NILs) that differ only in their (a)virulence (Jarquin-Barberena et al. 1991). Furthermore, isofemale-line-selection studies demonstrated that nematode virulence is genetically determined (Castagnone-Sereno et al. 1994). So far, the specific molecular mechanisms underlying (a)viru-lence against plant resistance genes are unknown in nematodes. On the contrary, a number of avirulence genes have been cloned in bacteria and fungi, and it has been proposed that the interaction between the products of the avirulence and resistance genes would activate a signal transduction pathway leading to $\mathrm{HR}$ in the plant cells, thus blocking the pathogen (Laugé and De Wit 1998; Leach and White 1996). Whether such a model system could apply to plant-parasitic nematodes, however, has not yet been elucidated.

In this study, amplified fragment length polymorphism (AFLP) fingerprinting of three pairs of $M$. incognita NILs was used to identify sequences differential between avirulent and virulent nematodes. In avirulent genotypes, a cDNA encoding a secretory protein whose sequence is characterized by internal repetitive motifs, named MAP-1, was cloned. Polyclonal 
antibodies raised against MAP-1 localized the protein in the amphidial secretions of infective second-stage juveniles (J2s), which indicates that MAP-1 may be involved in the early recognition steps between the plant and the nematode.

\section{RESULTS}

\section{AFLP fingerprinting and cloning of map-1 cDNA.}

To compare $M$. incognita avirulent and virulent NILs, AFLP markers were developed with all of the 256 combinations that could be generated with primers with two selective nucleotides. Each primer combination allowed the amplification of 50 to 120 fragments, with sizes ranging from 50 to $1,000 \mathrm{bp}$. A total of approximately 25,000 fragments were amplified, among which 17 were present in the three avirulent NILs and absent in the three virulent NILs, whereas 13 were present in two of the three avirulent NILs and absent in the corresponding virulent NILs. All were recovered from the gels, cloned, and sequenced. None of the 30 fragments showed homology with any known sequence in databases (data not shown).

The cloned AFLP fragments were used as probes in DNA blot experiments, and one of them showed significant polymorphism. This 820-bp fragment (C1) was generated with primer HindIII+GC, in combination with primer MseI+TG. AFLP analysis determined that this fragment was present in avirulent lines originating from Calissanne $(\mathrm{Cal})$, France, and Morelos (Mor), Mexico, and absent in the corresponding virulent NILs (Fig. 1). The marker was absent in either avirulent or virulent NIL from Kursk (Kur), Russia. With the use of the same primer combination as above, however, a second band (C2) was detected in the Kur avirulent line that was absent in the corresponding virulent NIL (Fig. 1). When used as a probe in DNA blot analysis, the $\mathrm{C} 1$ fragment hybridized to several DNA fragments in each nematode line. Three bands, ranging from approximately 7 to $12 \mathrm{~kb}$, were common to the six nematode lines (Fig. 2). A smaller band of approximately $2.5 \mathrm{~kb}$ was present in the three avirulent genotypes and absent in the three corresponding virulent NILs. A careful analysis revealed that the band in the Kur avirulent line was a bit smaller compared with the band in the Cal and Mor lines (Fig. 2). Because the C1 AFLP fragment generated a polymorphism that was differential between avirulent and virulent nematodes from the three pairs of NILs, we decided to concentrate our study on it.

In order to investigate whether the $\mathrm{C} 1$ fragment could correspond to (a fragment of) a gene, it was used as a probe to screen a cDNA library constructed from $M$. incognita $\mathrm{J} 2 \mathrm{~s}$. Seven positive clones were identified, and sequencing of the three longest ones revealed that they were highly identical, apart from deletions of approximately $100 \mathrm{bp}$ for one clone and $250 \mathrm{bp}$ for the second one in the $\mathrm{N}$-terminal region (both included the initiation site) (data not shown). Therefore, the one with the longest cDNA insert, named map-1 for Meloidogyne avirulence protein, was selected for further characterization.

\section{Predicted amino acid sequence of the map-1 clone.}

The full-length map-1 cDNA is 1,519 nucleotides long, with an open reading frame of 1,374 bp (Fig. 3). No splice leader sequence was observed. The predicted protein, MAP-1, is 458 amino acids (aa) long, with a theoretical molecular weight of $49 \mathrm{kDa}$ and a theoretical pI of 8.2. A computerassisted protein sequence similarity search revealed no significant homology with any known sequence in databases. The protein is characterized by its overall abundance of proline residues (78 residues, which represent approximately $17 \%$ of the whole sequence) and by the presence of 17 cysteine residues, which suggests that the tertiary structure should present significant folding. This hypothesis was supported by analysis from the PredictProtein program, which indicated that the putative protein should be globular. SignalP analysis showed that MAP-1 contained a predictive $\mathrm{N}$-terminal eu-

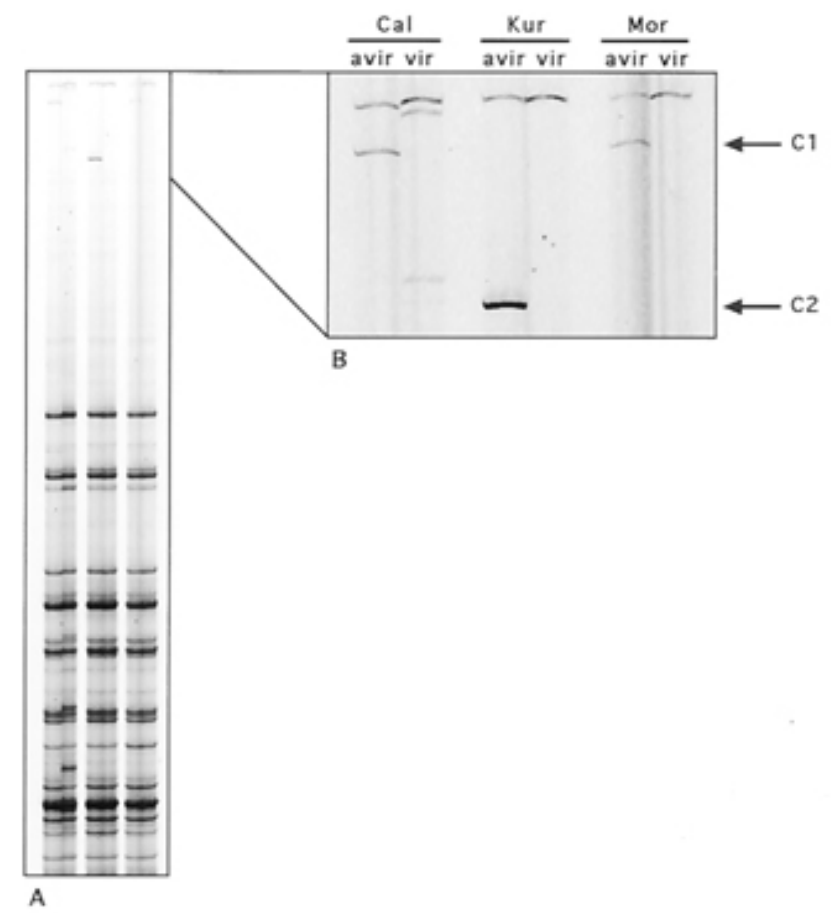

Fig. 1. Amplified fragment length polymorphism fingerprinting of Meloidogyne incognita avirulent and virulent near-isogenic lines. A, Amplification produced with primers HindIII+GC and MseI+TG. B, Enlargement of the area of interest. Bands specific for avirulent genotypes $(\mathrm{C} 1$ and $\mathrm{C} 2)$ are indicated by arrows.

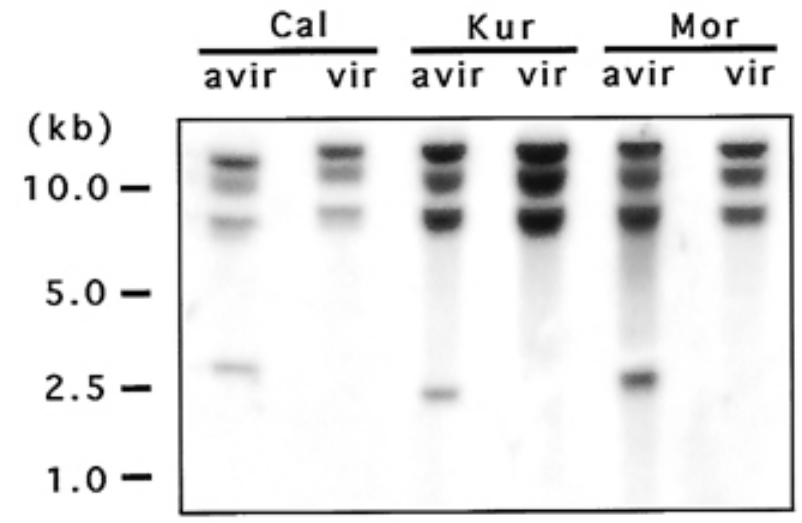

Fig. 2. Southern blot hybridization of genomic DNA from Meloidogyne incognita avirulent and virulent near-isogenic lines. DNA $(5 \mu \mathrm{g})$ was digested with $E c o$ RI, fractionated in $1 \%$ agarose gel, transferred onto a nylon membrane, and probed with the ${ }^{32} \mathrm{P}$-labeled $\mathrm{C} 1$ amplified fragment. 
karyotic secretion signal sequence of 17 aa. The HMMTOP analysis confirmed that the 17 first residues constituted the only putative transmembrane domain of the protein. The internal part of MAP-1 showed two highly conserved motives of 58 aa each, located at residues 124 to 181 and 208 to 265 , respectively (Fig. 3). These two repeats shared a high identity level since 52 of 58 positions $(89.6 \%)$ were conserved between them. Moreover, they were separated by two highly conserved (12 of 13 identical residues), tandemly repeated motifs of 13 aa each (Fig. 3). A third truncated repeat showing only the first five residues of the 13 aa motif, was located just after the second large repeat of 58 aa, starting at position 266 (Fig. 3).

\section{Expression analysis of map-1.}

Transcription of the map- 1 gene was analyzed by reverse transcription polymerase chain reaction (RT-PCR) on mRNA from $\mathrm{J} 2 \mathrm{~s}$ from the three pairs of $M$. incognita NILs with primers $\mathrm{m} 1$ and $\mathrm{m} 3$ (Fig. 3). A fragment of approximately 1,200 bp was amplified from all samples. Amplification products of the

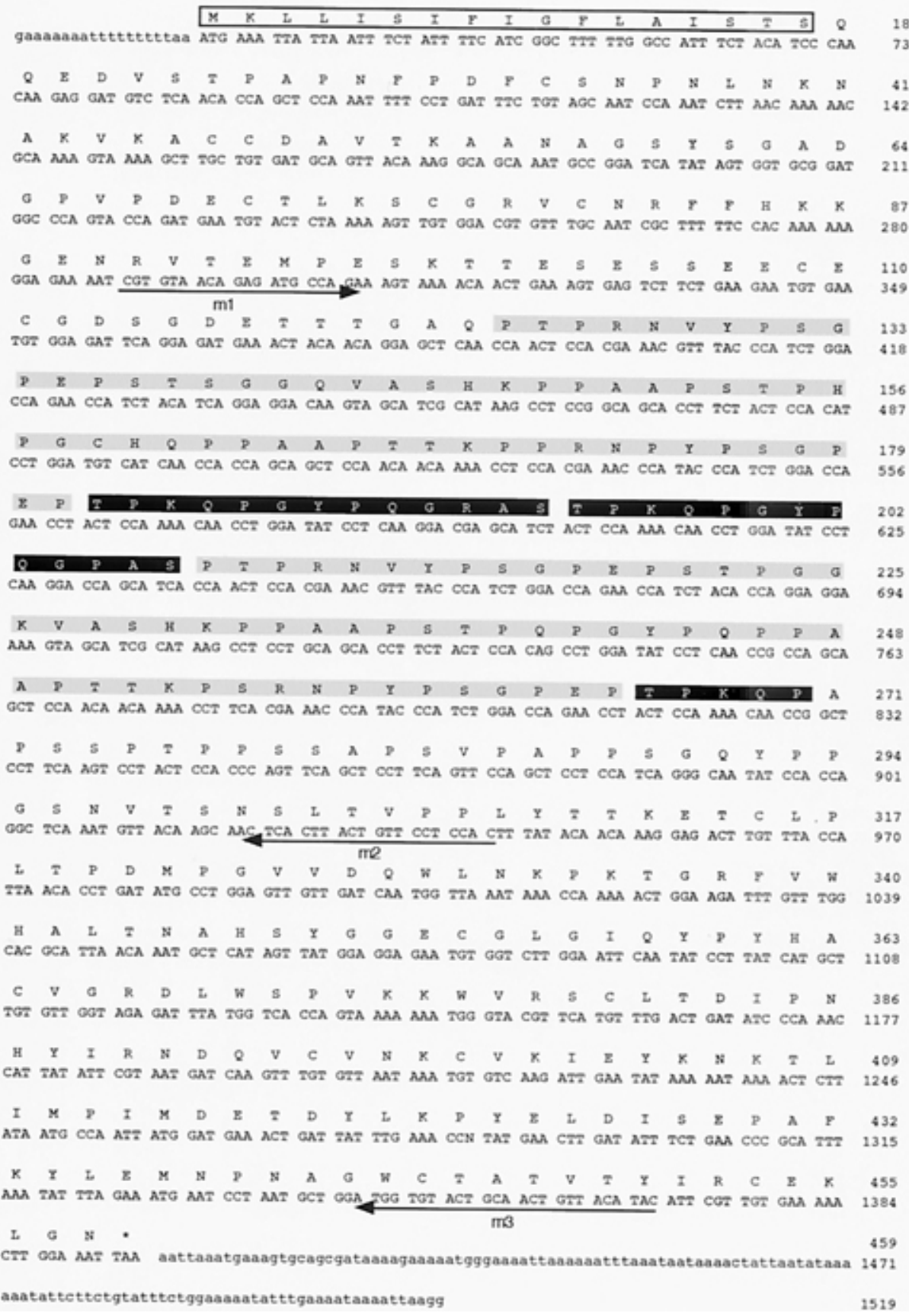

Fig. 3. Meloidogyne incognita map-1 cDNA and predicted amino acid sequence. The putative secretion signal sequence is indicated by a white box. The gray and black boxes show the 58 and 13 amino acid-long repetitive motives, respectively. $\mathrm{m} 1, \mathrm{~m} 2$, and $\mathrm{m} 3$ primers used in either polymerase chain reaction (PCR) or reverse transcription PCR experiments are indicated by arrows. TAA termination signal is marked with an asterisk. Nucleotide sequence has been submitted to the EMBL database as accession number AJ278663. 
expected 1,079-bp size were obtained from the avirulent lines $\mathrm{Cal}$ and Mor, and a 850-bp fragment was observed in the avirulent line Kur (Fig. 4).

\section{Distribution of map-1-related sequences in nematode species.}

The presence of map-1-related sequences in a range of nematode genomes was studied by PCR with primers $\mathrm{m} 1$ and $\mathrm{m} 2$. RKN species other than $M$. incognita, either controlled by the tomato $M i$ resistance gene ( $M$. arenaria and $M$. javanica) or not (M. hapla and M. fallax), were tested. Also used were genomic DNAs from the plant-parasitic species Globodera pallida and Xiphinema index and from the bacteriophagous species Caenorhabditis elegans. Genomic DNA from the avirulent $M$. incognita Mor line was used as a positive control. Amplifications were obtained with DNA templates from $M$. incognita, $M$. arenaria (three isolates), and $M$. javanica (four isolates) (Fig. 5). Conversely, no product was amplified with the two other Meloidogyne spp. nor with the additional nematode genera tested. With $M$. incognita DNA, two bands of approximately 750 and 650 bp were obtained. The 750-bp band also was present in all of the $M$. arenaria and $M$. javanica isolates tested. Moreover, a fragment of approximately 725 bp was amplified from the genome of $M$. arenaria and $M$. javanica isolates and an additional 680-bp fragment was amplified solely from the $M$. arenaria isolate a2.

\section{Immunological localization of MAP-1.}

A polyclonal antiserum was raised against a synthetic peptide corresponding to aa 180 to 194 of the MAP-1 protein. To determine the location of the MAP-1 protein in the nematode, sections of freshly hatched $\mathrm{J} 2 \mathrm{~s}$ of $M$. incognita were treated with the polyclonal antisera in immunofluorescence assays. The antibodies reacted strongly and specifically with the anterior end of the nematodes, and the analysis revealed that the observed immunofluorescence consisted of two close signals that correspond to the location of secretions produced by the amphids of the nematode (Fig. 6). Negative and positive controls were used in all assays. No binding was observed with either the control solution without primary antibody or the nonimmune rabbit serum, and the labeling pattern obtained with $6 \mathrm{D}_{4}$, a monoclonal antibody specific to secretory granules formed in RKN esophageal glands (Davis et al. 1992), was restricted to the esophageal glands of $\mathrm{J} 2 \mathrm{~s}$ (data not shown).

\section{DISCUSSION}

In this study, an AFLP-based differential strategy was used, which resulted in the cloning of map- 1 that represents a putative avirulence gene from the RKN $M$. incognita. The predicted MAP-1 protein does not show any significant homology in databases, but contains a predictive N-terminal secretion signal peptide and two classes of repetitive motifs. Immunolocalization experiments confirmed that the MAP-1 protein is secreted by amphids, which are the principal chemosensory organs of the nematode (Perry 1996). Because of the mitotic parthenogenetic mode of reproduction of this species, no genetic approach could be designed to localize markers linked to the (a)virulence gene(s). Therefore, the comparative analysis of genotypes differing only in their ability or inability to overcome the plant resistance gene was an alternative approach to cloning such gene(s) on the basis of the assumption that any difference between them should be related to this character (Castagnone-Sereno et al. 1997). Clearly, the efficiency of such a strategy relies on the nearisogenicity of the biological material to be analyzed. In that respect, a continuous effort of selection and maintenance of avirulent and virulent $M$. incognita NILs has been undertaken in our laboratory for many years. In this study, in order to select polymorphic molecular markers directly related to the character of interest, we used three avirulent isolates from very distant geographic origin to select three pairs of NILs. In a previous AFLP study, we demonstrated that the average rate of polymorphism among seven $M$. incognita avirulent isolates was approximately $4.4 \%$ with HindIII and $\mathrm{MseI}$ as restriction enzymes (Semblat et al. 1998). Therefore, the observation that as few as $0.1 \%$ of 25,000 AFLP markers generated with the same restriction enzymes were polymorphic between avirulent and virulent NILs and that such polymorphisms were conserved between two or three pairs of NILs validated the nearisogenicity of these genotypes at the molecular level and thus the interest of such material for the development of a differential cloning strategy.

The AFLP, DNA blot analysis, and RT-PCR data are all congruent with the hypothesis that a (coding) sequence present in the three avirulent lines is lacking in the corresponding virulent lines. Preliminary analysis of the C2 AFLP fragment (from the Kur avirulent line) revealed its very high level of sequence identity with the $\mathrm{C} 1$ fragment (amplified from the $\mathrm{Cal}$ and Mor avirulent lines) and that the size difference between them (approximately $250 \mathrm{bp}$ ) is mainly a result of the deletion of some of the repetitive motifs in C2 (data not shown). This result confirms that the same sequence (in the $\mathrm{Cal}$ and Mor lines) or a very related one (in the Kur line) occurs in the genome of the three avirulent lines. In addition,

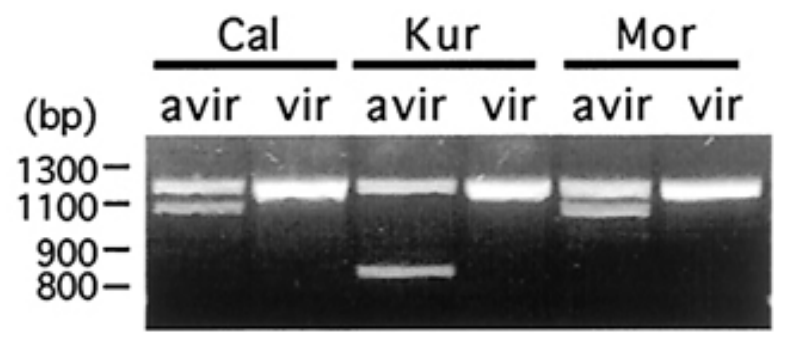

Fig. 4. Reverse transcription polymerase chain reaction analysis of Meloidogyne incognita avirulent and virulent near-isogenic lines. Equivalent amounts of RNA were used for synthesis of first-strand cDNAs. $\mathrm{m} 1$ and $\mathrm{m} 3$ primers were used for amplification.

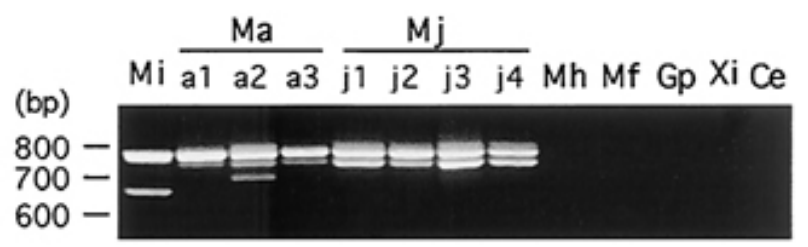

Fig. 5. Polymerase chain reaction analysis of map-1-related sequences in nematode genomes. Equivalent amounts of genomic DNA were used for all nematode species and isolates. Genomic DNA from Meloidogyne incognita ( $\mathrm{Mi}$ avirulent Morelos isolate) was used as a positive control. 
PCR experiments with map- 1 -specific primers revealed the presence of homologous sequences only in $M$. arenaria, $M$. incognita, and $M$. javanica isolates. No amplification was observed with other Meloidogyne spp. (i.e., M. hapla or M. fallax), other plant-parasitic nematode genera (i.e., Globodera or Xiphinema), or the free-living species $C$. elegans. Interestingly, the presence of map- 1 homologous fragments appears restricted to the three RKN species that are controlled by the tomato $\mathrm{Mi}$ resistance gene. Although not demonstrative, such correlations reinforce the hypothesis that map- 1 is indeed a very good candidate for an avirulence gene in $M$. incognita. The 16 remaining AFLP fragments that were present in the three avirulent NILs and absent in the three virulent NILs, however, were not discarded as irrelevant to (a)virulence of the nematode and their analysis is currently being conducted in the laboratory.

The amphids are the primary anterior sense organs of the nematodes. They are located bilaterally on either side of the oral opening, and each amphid opens to the exterior via a
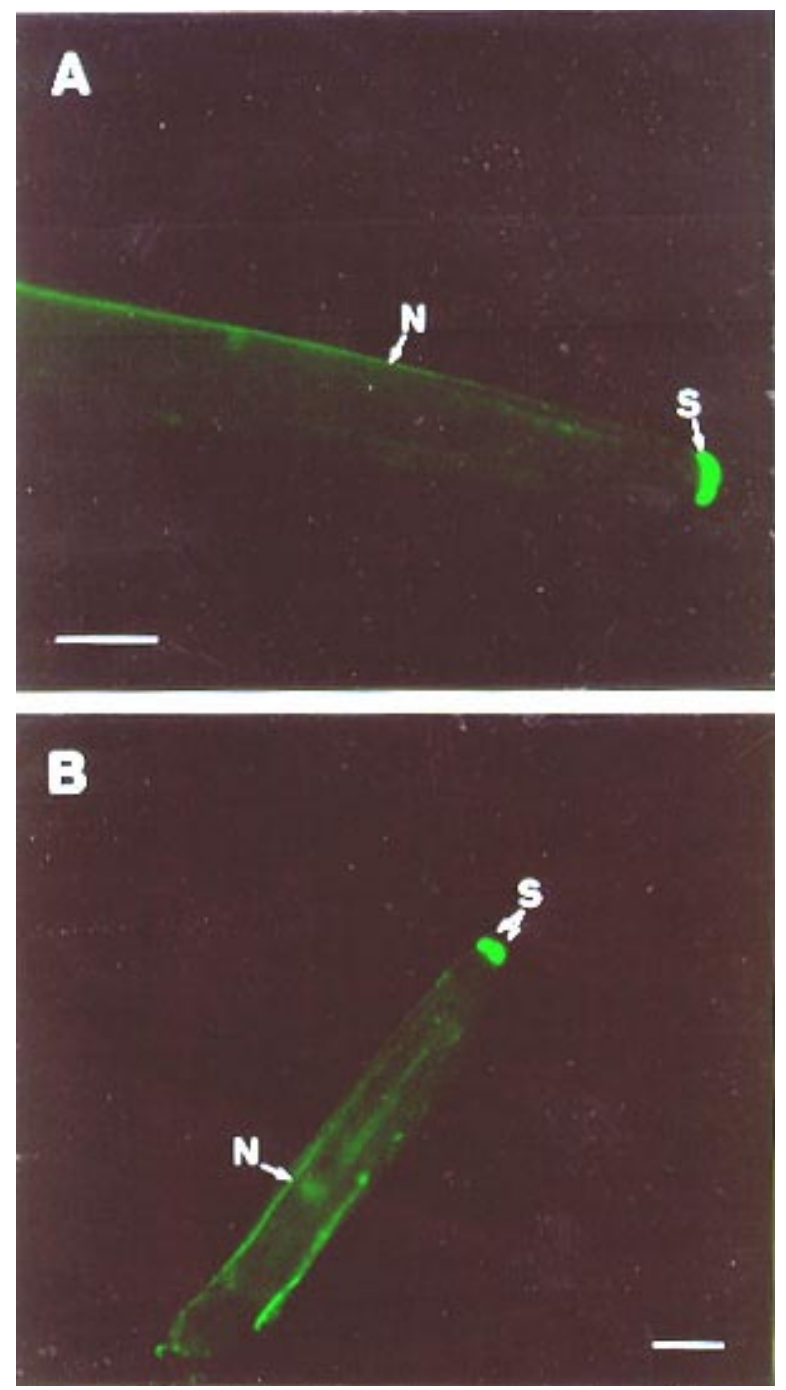

Fig. 6. Immunolocalization of the MAP-1 protein in Meloidogyne incognita second-stage juveniles. A, Labeling of the anterior end of a nematode with the polyclonal antiserum. B, Labeling bound to the amphidial secretions of the nematode. $\mathrm{N}=$ nematode body; $\mathrm{S}=$ amphidial secretions; horizontal bars $=15 \mu \mathrm{m}$. prominent pore (Bird and Bird 1991). The amphidial cavity contains dendritic processes that are bathed in secretions, apparently produced by the sheath cell. Experimental work on $C$. elegans demonstrated the chemosensory function of amphids (Bargmann et al. 1990), although there is evidence that amphidial secretions may serve other functions (Perry 1996). In plant-parasitic nematodes, neither the composition of amphidial secretions nor their role in the host-parasite interaction have been fully elucidated. Previous studies showed the occurrence of carbohydrate residues in the amphidial secretions of several RKN species (McClure and Stynes 1988). More recently, a glycoprotein, gp32, was specifically associated to the amphids of six Meloidogyne spp., but not in the representatives of eight other nematode genera, including the closely related cyst nematodes Globodera and Heterodera (Stewart et al. 1993a). Further studies suggest that gp32 is involved in the chemosensory process by which $M$. incognita J2s locate tomato roots (Stewart et al. 1993b). Immunolocalization of MAP-1 confirmed the prediction that it should be a secreted protein because of the presence of a putative $\mathrm{N}$-terminal signal peptide. This new protein identified here indicates that the amphidial secretions of RKN are composed of a number of different components, probably with different functions. The distribution of sequences homologous to the map- 1 gene was restricted to the three Meloidogyne spp. controlled by the $\mathrm{Mi}$ gene, suggesting a specialized function for the protein in relation to the resistance gene. Because the first visible indications of HR occur approximately $12 \mathrm{~h}$ after the inoculation of roots with J2s (Williamson 1998), it is tempting to speculate that MAP-1 could be involved in the early recognition steps between resistant tomatoes and avirulent nematodes. Further studies are needed, however, to determine the actual function of the $M$. incognita MAP-1 protein in the plant-nematode interaction.

One way to demonstrate the role of map- 1 in avirulence would be to transform virulent nematodes with the gene and inoculate them in $M i$-resistant tomatoes to test whether they would elicit HR. However, although efficient transformation of $C$. elegans through microinjection of foreign DNA into the gonads has been demonstrated (Mello et al. 1991), a transformation system is not yet available for plant-parasitic nematodes. An alternative strategy is to directly test the functionality of the MAP-1 protein in tomato via a plant-expression system such as the PVX vector (Chapman et al. 1992). The resulting HR phenotype in resistant tomatoes would indicate the recognition of the protein as an avirulence factor.

Our data raises questions about the genetic mechanisms involved during the selection process of avirulent and virulent NILs. Hence, because of the parthenogenesis, how can the map-1 gene be present or absent in sister progenies raised from a single nematode? It is possible that the gene is located in an unstable region of the genome that can be deleted without dramatically affecting the viability of the nematode. Indeed, the occurrence of a truncated repetitive motif in map-1 as well as the deletion in the sequence of the fragment amplified in the avirulent line from Kur are in agreement with such an hypothesis. The genome of RKN has been subjected to extensive cytological modifications involving, among others, aneuploidy and chromosome rearrangements (Triantaphyllou 1985). In addition, breakage without reassociation and loss of some chromosome fragments are not exceptional in these 
species (A. Dalmasso, personal communication). As a result of the holocentric nature of Meloidogyne spp. chromosomes, the loss of a DNA fragment comprising the map- 1 gene would be maintained in subsequent generations and contribute to the emergence of a virulent clone. Although it remains to be demonstrated, the hypothesis that virulent $M$. incognita lines arose from avirulent ones through some unusual cytogenetic event is to be considered.

\section{MATERIALS AND METHODS}

\section{Nematodes.}

All the RKN isolates used in this study came from the collection of the Institut National de la Recherche Agronomique (INRA) in Antibes, France (Table 1). They were characterized at the species level according to their isoesterase electrophoretic pattern (Dalmasso and Bergé 1978) and grown on tomato roots (cv. Saint Pierre) in a greenhouse. Three $M$. incognita isolates, Cal, Kur, and Mor, were selected on the basis of their avirulence against the tomato $M i$ resistance gene. From each avirulent population, NIL was selected for virulence on the $M i$-resistant tomato cv. Piersol, according to the procedure described by Jarquin-Barberena et al. (1991).

Eggs were collected after treatment of the egg masses in $0.5 \% \mathrm{NaOCl}$ and rinsed with distilled water. J2s were then hatched in vitro on $10-\mu \mathrm{m}$ sieves in $0.7 \%$ streptomycin sulfate, concentrated by centrifugation, aliquoted, and stored at $-80^{\circ} \mathrm{C}$ until further use.

\section{Nucleic acid purification.}

For each RKN population, $200 \mu \mathrm{l}$ of $\mathrm{J} 2 \mathrm{~s}$ were grounded in liquid nitrogen with a mortar and pestle. Total genomic DNA was extracted from the resulting powder by a phenolchloroform procedure, as described in Sambrook et al. (1989). Genomic DNAs from $G$. pallida and from $X$. index and $C$. elegans were provided by E. Grenier and D. Esmenjaud, respectively. mRNAs were purified from J2s with the Quick Prep Micro mRNA Purification kit (Pharmacia Biotech, Uppsala, Sweden), according to the manufacturer's instructions.

\section{AFLP procedure and cloning of polymorphic DNA fragments.}

The three pairs of avirulent and virulent $M$. incognita NILs were compared with AFLP markers. The AFLP procedure was performed essentially as described previously (Semblat et al. $1998)$ with minor modifications. Nematode DNAs $(1 \mu \mathrm{g})$ were digested with HindIII and MseI restriction endonucleases. MseI adapters and HindIII biotinylated adapters were ligated to the digested fragments. Biotinylated fragments were selected by streptavidin M-280 beads (Dynal, Oslo, Norway) with STEX buffer (1 M NaCl; $10 \mathrm{mM}$ Tris, $\mathrm{pH} 8.0 ; 1 \mathrm{mM}$ EDTA; and $0.1 \%$ [vol/vol] Triton X-100). Magnetic beads were resuspended in $200 \mu \mathrm{l}$ of $\mathrm{H}_{2} \mathrm{O}$ and stored at $-20^{\circ} \mathrm{C}$ until use. Primers with no selective nucleotide were used for the first amplification step on $5 \mu \mathrm{l}$ of bead suspension, and primers with two selective nucleotides were used for the second amplification step. All the possible primer combinations $\left(4^{2} \times\right.$ $4^{2}=256$ ) were tested in these experiments. The PCR products were electrophoresed in $4.75 \%$ denaturing polyacrylamide gels. The gels were dried on 3MM paper (Whatman plc, Maidstone, Kent, U.K.) under vacuum and exposed to X-ray film to produce autoradiographs.
DNA fragments that were polymorphic within two or three of the avirulent and virulent NILs were extracted from the dried polyacrylamide gel by excising and rehydrating the corresponding zone in $50 \mu \mathrm{l}$ of Tris-EDTA buffer. DNA was recovered by centrifugation after cooled in liquid nitrogen and thawed at room temperature (three times). Four microliters of the supernatant were reamplified in the same conditions and with the same primer combination as in the AFLP procedure. The resulting band was cloned into the pGEM-T vector (Promega, Charbonnieres, France).

\section{DNA analysis and sequencing.}

Standard procedures were used for restriction endonuclease digestion, electrophoresis, transfer to nylon membrane, radioactive labeling, and hybridization (Sambrook et al. 1989). Hybridizations were performed overnight at $65^{\circ} \mathrm{C}$. Conditions for final washing consisted of $65^{\circ} \mathrm{C}$ in $1 \times$ SSPE buffer $(2 \mathrm{mM}$ EDTA; $0.3 \mathrm{M} \mathrm{NaCl}$; and $18 \mathrm{mM} \mathrm{NaH}_{2} \mathrm{PO}_{4}, \mathrm{pH} \mathrm{7.4)}$ and $1 \%$ sodium dodecyl sulfate.

DNA and cDNA clones of interest were sequenced by Genome Express (Grenoble, France). Homology searches were performed within the EMBL and GenBank databases by the BLAST algorithm (Altschul et al. 1990). Predictions for signal peptide, molecular weight and pI, secondary structure, and transmembrane domains were run by programs accessible on the Internet such as SignalP (Nielsen et al. 1997), PeptideMass (Wilkins et al. 1997), HMMTOP (Tusnady and Simon 1998), and PredictProtein (Rost and Sander 1993; Rost and Sander 1994), respectively.

\section{cDNA library screening.}

A pcDNAII (Invitrogen, Carlsbad, CA, U.S.A.) cDNA library of $M$. incognita J2s (Ding et al. 1998) was used to identify clones of interest. Approximately 20,000 colonies were plated and transferred onto nylon membrane following standard procedures (Smith and Summers 1980) and screened

Table 1. Nematodes used in this study

\begin{tabular}{|c|c|c|c|}
\hline Species & Code & Geographic origin & $\begin{array}{l}\text { (A)virulence } \\
\text { against the to- } \\
\text { mato } M i \text { gene }\end{array}$ \\
\hline \multirow{3}{*}{$\begin{array}{c}\text { Meloidogyne } \\
\text { arenaria }\end{array}$} & a1 & Espiguette, France & Avirulent \\
\hline & $\mathrm{a} 2$ & Grau-du-Roi, France & Virulent \\
\hline & a3 & Monteux, France & Avirulent \\
\hline M. fallax & Mf & Paimpol, France & \\
\hline M. hapla & $\mathrm{Mh}$ & La Môle, France & \\
\hline \multirow[t]{3}{*}{ M. incognita } & Cal & Calissanne, France & Avirulent \\
\hline & Kur & Kursk, Russia & Avirulent \\
\hline & Mor & Morelos, Mexico & Avirulent \\
\hline \multirow[t]{4}{*}{ M. javanica } & $\mathrm{j} 1$ & La Réunion Island & Avirulent \\
\hline & $\mathrm{j} 2$ & Oualidia, Morocco & Avirulent \\
\hline & $\mathrm{j} 3$ & The Canary Islands & Virulent \\
\hline & $\mathrm{j} 4$ & Turkey & Virulent \\
\hline $\begin{array}{l}\text { Globodera pal- } \\
\quad \text { lida }\end{array}$ & Gp & $?$ & \\
\hline Xiphinema index & $\mathrm{Xi}$ & Fréjus, France & \\
\hline $\begin{array}{l}\text { Caenorhabditis } \\
\text { elegans }\end{array}$ & $\mathrm{Ce}$ & $?$ & \\
\hline
\end{tabular}


with $\left[{ }^{32} \mathrm{P}\right] \mathrm{dCTP}$-labeled genomic polymorphic AFLP fragments used as probes. Conditions for hybridization and washes were in accordance with the procedure described above.

\section{PCR and RT-PCR amplifications.}

The oligonucleotide primers $\mathrm{m} 1$ (5'-CGTGTAACAGAGATGCCAGA-3'), m2 (5'-GTGGAGGAACAGTAAGTGAG$\left.3^{\prime}\right)$, and $\mathrm{m} 3$ (5'-GTATGTAACAGTTGCAGTACACC-3') were designed from the map-1 gene sequence (Fig. 3). All PCR and RT-PCR experiments were performed with Taq polymerase (Appligene Oncor, Illkirch, France) for $3 \mathrm{~min}$ at $94^{\circ} \mathrm{C}, 30$ cycles at $94^{\circ} \mathrm{C}$ for $1 \mathrm{~min}, 60^{\circ} \mathrm{C}$ for $1 \mathrm{~min}, 72^{\circ} \mathrm{C}$ for 1 $\min 30 \mathrm{~s}$, and a final elongation of $5 \mathrm{~min}$ at $72^{\circ} \mathrm{C}$ in a thermal cycler. The reaction contained $0.25 \mathrm{mM}$ dNTPs each and 0.3 $\mu \mathrm{M}$ oligonucleotide primers each.

Amplification of genomic DNA was conducted on $10 \mathrm{ng}$ of DNA from each nematode species tested with primers $\mathrm{m} 1$ and $\mathrm{m} 2$.

Transcript accumulation in the three pairs of NILs was studied by RT-PCR. First-strand cDNAs were synthesized from $1 \mu \mathrm{g}$ of mRNA by the Reverse Transcription System (Promega), and one-tenth of the reaction volume was used as template for amplification. To avoid amplification as a result of genomic DNA contamination, RT-PCR reactions were performed with primers $\mathrm{m} 1$ and $\mathrm{m} 3$, which overlap intron sequences as deduced from the genomic amplification product sequence.

\section{Antiserum production.}

Polyclonal antibodies to a synthetic peptide designed from the map-1 sequence were produced by Eurogentec (Herstal, Belgium). The peptide was designed according to its high antigenic potential, as determined by Lasergene software (DNAStar, Madison, WI, U.S.A), corresponding to aa 180 to 194 of the MAP-1 protein (EPTPKQPGYPQGRAS). To produce polyclonal antibodies, two rabbits were injected with the synthetic peptide linked to keyhole limpet hemocyanin (Sigma, Saint Quentin Fallavier, France). Complete Freund's adjuvant was used for the initial injection and incomplete Freund's adjuvant was used for the two subsequent boost injections.

\section{Immunofluorescence study.}

The $M$. incognita $\mathrm{J} 2 \mathrm{~s}$ were fixed overnight at $4^{\circ} \mathrm{C}$ in $2 \%$ paraformaldehyde in phosphate-buffered saline (PBS) (136 $\mathrm{mM} \mathrm{NaCl}, 1.5 \mathrm{mM} \mathrm{KH} \mathrm{PO}_{4}, 2.7 \mathrm{mM} \mathrm{KCl}$, and $1 \mathrm{mM}$ $\mathrm{Na}_{2} \mathrm{HPO}_{4}$ ). They were washed three times in M9 buffer (42 $\mathrm{mM} \mathrm{Na} \mathrm{HPO}_{4} ; 22 \mathrm{mM} \mathrm{KH}_{2} \mathrm{PO}_{4} ; 85 \mathrm{mM} \mathrm{NaCl} ; 1 \mathrm{mM} \mathrm{MgSO}$; and $7 \mathrm{H}_{2} \mathrm{O}, \mathrm{pH}$ 7.0) and once in distilled water, then transferred to aluminum foil dishes for drying in a thin layer. Dried nematodes were cut into sections and permeabilized with 2 $\mathrm{mg}$ of proteinase $\mathrm{K}$ per $\mathrm{ml}$ and a cold methanol and acetone treatment. The acetone was removed, and sections were resuspended and incubated overnight at $-20^{\circ} \mathrm{C}$ in $1 \mathrm{mg}$ of horse serum-phenylmethylsulfonyl fluoride per $\mathrm{ml}$ to block nonspecific antibody binding sites. Approximately 200 sections were placed in 1.5 microcentrifuge tubes, and $450 \mu \mathrm{l}$ of PBS and 50 $\mu l$ of primary antibody serum were added per tube and sections incubated overnight at room temperature with gentle agitation. Sections were washed three times for $5 \mathrm{~min}$ each in PBST buffer (PBS with 0.1\% Tween 20) and resuspended in 1 $\mathrm{ml}$ of fluorescein isothiocyanate (FITC) conjugate of goatanti-rabbit immunoglobulin G (Sigma) diluted to $1 / 200$ in PBSTB buffer (PBST with $0.1 \%$ bovine serum albumin). Sections were agitated in the presence of the FITC antibody at room temperature in the dark for $3 \mathrm{~h}$ and rinsed twice in PBST and once in distilled water. Antibody-treated sections were transferred to multitest polylysine-coated slides and observed by fluorescence microscopy. Negative controls included no primary antibody and nonimmune rabbit serum. The positive control was $6 \mathrm{D}_{4}$, a monoclonal antibody specific to secretory granules formed in root-knot nematode esophageal glands (Davis et al. 1992).

\section{LITERATURE CITED}

Altschul, S. F., Gish, W., Miller, W., Myers, E. W., and Lipman, D. J. 1990. Basic local alignment search tool. J. Mol. Biol. 215:403-410.

Bargmann, C. I., Thomas, J. H., and Horvitz, H. R. 1990. Chemosensory cell function in the behavior and development of Caenorhabditis elegans. Cold Spring Harbor Symp. Quant. Biol. 55:529-538.

Bird, A. F., and Bird, J. 1991. The Structure of Nematodes. 2nd ed. Academic Press, San Diego.

Castagnone-Sereno, P., Abad, P., Bakker, J., Williamson, V. M., Gommers, F. J., and Dalmasso, A. 1997. Genetic and molecular strategies for the cloning of (a)virulence genes in sedentary plantparasitic nematodes. Pages 167-175 in: Cellular and Molecular Aspects of Plant-Nematode Interactions. C. Fenoll, F. M. W. Grundler, and S. A. Ohl, eds. Kluwer Academic Publishers, Dordrecht, The Netherlands.

Castagnone-Sereno, P., Wajnberg, E., Bongiovanni, M., Leroy, F., and Dalmasso, A. 1994. Genetic variation in Meloidogyne incognita virulence against the tomato $M i$ resistance gene: Evidence from isofemale line selection studies. Theor. Appl. Genet. 88:749-753.

Chapman, S., Kavanagh, T., and Baulcombe, D. C. 1992. Potato virus X as a vector for gene expression in plants. Plant J. 2:549-557.

Dalmasso, A., and Bergé, J. B. 1978. Molecular polymorphism and phylogenetic relationship in some Meloidogyne spp.: Application to the taxonomy of Meloidogyne. J. Nematol. 10:323-332.

Davis, E. L., Aron, L. M., Pratt, L. H., and Hussey, R. S. 1992. Novel immunization procedures used to develop monoclonal antibodies that bind to specific structures in Meloidogyne spp. Phytopathology 82:1244-1250.

Ding, X., Shields, J., Allen, R., and Hussey, R. S. 1998. A secretory cellulose-binding protein cDNA cloned from the root-knot nematode (Meloidogyne incognita). Mol. Plant-Microbe Interact. 11:952-959.

Eddaoudi, M., Ammati, M., and Rammah, A. 1997. Identification of the resistance breaking populations of Meloidogyne on tomatoes in Morocco and their effect on new sources of resistance. Fundam. Appl. Nematol. 20:285-289.

Jarquin-Barberena, H., Dalmasso, A., De Guiran, G. and Cardin, M. C. 1991. Acquired virulence in the plant parasitic nematode Meloidogyne incognita. I. Biological analysis of the phenomenon. Rev. Nematol. 14:299-303.

Kaloshian, I., Williamson, V. M., Miyao, G., Lawn, D. A., and Westerdahl, B. B. 1996. Resistance-breaking nematodes identified in California tomatoes. Calif. Agric. 50:18-19.

Lamb, C. J. 1994. Plant disease resistance genes in signal perception and transduction. Cell 76:419-422.

Laugé, R., and De Wit, P. J. G. M. 1998. Fungal avirulence genes: Structure and possiblefunction. Fungal Genet. Biol. 24:285-297.

Leach, J. E., and White, F. F. 1996. Bacterial avirulence genes. Annu. Rev. Phytopathol. 34:153-179.

McClure, M. A., and Stynes, B. A. 1988. Lectin binding sites on the amphidial exudates of Meloidogyne. J. Nematol. 20:321-326.

Mello, C. C., Kramer, J. M., Stinchcomb, D., and Ambros, V. 1991 Efficient gene transfer in Caenorhabditis elegans: Extrachromosomal maintenance and integration of transforming sequences. EMBO J. 10:3959-3970.

Milligan, S. B., Bodeau, J., Yaghoobi, J., Kaloshian, I., Zabel, P., and Williamson, V. M. 1998. The root-knot nematode gene $\mathrm{Mi}$ from to- 
mato is a member of the leucine-zipper, nucleotide binding, leucinerich repeat family of plant genes. Plant Cell 10:1307-1319.

Nielsen, H., Engelbrecht, J., Brunak, S., and vonHeijne, G. 1997. Identification of prokaryotic and eukaryotic signal peptides and prediction of their cleavage sites. Protein Eng. 10:1-6.

Perry, R. N. 1996. Chemoreception in plant-parasitic nematodes. Annu. Rev. Phytopathol. 34:181-199.

Roberts, P. A. 1992. Current status of the availability, development and use of host plant resistance to nematodes. J. Nematol. 24:213-227.

Rost, B., and Sander, C. 1993. Prediction of protein secondary structure at better than 70\% accuracy. J. Mol. Biol. 232:584-599.

Rost, B., and Sander, C. 1994. Combining evolutionary information and neural networks to predict protein secondary structure. Proteins 19:55-77.

Sambrook, J., Fritsch, E. F., Maniatis, T. 1989. Molecular Cloning: A Laboratory Manual, 2nd ed. Cold Spring Harbor Laboratory, Cold Spring Harbor, NY, U.S.A.

Semblat, J. P., Wajnberg, E., Dalmasso, A., Abad, P., and CastagnoneSereno, P. 1998. High resolution DNA fingerprinting of parthenogenetic root-knot nematodes using AFLP. Mol. Ecol. 7:119-125.

Smith, G. E., and Summers, M. D. 1980. The bidirectional transfer of DNA and RNA to nitrocellulose or diazobenzylomethyl paper. Anal. Biochem. 109:123-129.

Stewart, G. R., Perry, R. N., Alexander, J., and Wright, D. J. 1993a. A glycoprotein specific to the amphids of Meloidogyne species. Parasitology 106:405-412.

Stewart, G. R., Perry, R. N., and Wright, D. J. 1993b. Studies on the amphid specific glycoprotein gp32 in different life-cycle stages of Meloidogyne species. Parasitology 107:573-578.

Triantaphyllou, A. C. 1985. Cytogenetics, cytotaxonomy and phylogeny of root-knot nematodes. Pages 113-126 in: An Advanced Treatise on Meloidogyne. Vol. 1. J. N. Sasser, and C. C. Carter, eds. North Carolina State University Graphics, Raleigh, U.S.A.

Tusnady, G. E., and Simon, I. 1998. Principles governing amino acid composition of integral membrane proteins: Application to topology prediction. J. Mol. Biol. 283:489-506.

Tzortzakakis, E. A., and Gowen, S. R. 1996. Occurrence of a resistancebreaking pathotype of Meloidogyne javanica on tomatoes in Crete, Greece. Fundam. Appl. Nematol. 19:283-288.

Wilkins, M. R., Lindskog, I., Gasteiger, E., Bairoch, A., Sanchez, J. C., Hochstrasser, D. F., and Appel, R. D. 1997. Detailed peptide characterization using PEPTIDEMASS: A world-wide web accessible tool. Electrophoresis 18:403-408.

Williamson, V. M. 1998. Root-knot nematode resistance genes in tomato and their potential for future use. Annu. Rev. Phytopathol. 36:277293.

Williamson, V. M., and Hussey, R. S. 1996. Nematode pathogenesis and resistance in plants.Plant Cell 8:1735-1745. 